\title{
CLINICAL AND EPIDEMIOLOGICAL CHARACTERISTICS OF COVID-19 DURING THE EARLY PHASE OF THE SARS-COV-2 PANDEMIC: A CROSS-SECTIONAL STUDY AMONG MEDICAL SCHOOL PHYSICIANS AND RESIDENTS EMPLOYED IN A REGIONAL REFERENCE TEACHING HOSPITAL IN NORTHERN ITALY
}

\author{
GUGLIELMO DINI ${ }^{1,2}$, ALFREDO MONTECUCCO ${ }^{1,2}$, ALBORZ RAHMANI $^{1,2}$, CHIARA BARLETTA ${ }^{1,2}$, \\ LUCA PELLEGRINI ${ }^{1,2}$, NICOLETTA DEBARBIERI ${ }^{2}$, ANDREA ORSI ${ }^{1,3}$, PATRIZIA CALIGIURI $^{3}$, \\ SERENA VARESANO ${ }^{1,3}$, ALESSIA MANCA ${ }^{2}$, MARIA PAOLA VARGIU ${ }^{2}$, PIA DI CARLO ${ }^{1,2}$, EMANUELA MASSA ${ }^{1}$, \\ GIANCARLO ICARDI ${ }^{1,3}$, and PAOLO DURANDO ${ }^{1,2}$
}

${ }^{1}$ University of Genoa, Genoa, Italy

Department of Health Sciences (DISSAL)

${ }^{2}$ IRCCS Ospedale Policlinico San Martino, Genoa, Italy

Occupational Medicine Unit

${ }^{3}$ IRCCS Ospedale Policlinico San Martino, Genoa, Italy

Hygiene Unit

\begin{abstract}
Objectives: The aim of the study was to evaluate the clinical presentation and burden of SARS-CoV-2 infections among medical school physicians and residents, mainly young medical doctors. The awareness of COVID-19 clinical manifestations can improve the early detection of mild cases, possibly reducing further transmission to colleagues and patients. Material and Methods: The study was carried out in March-May 2020, involving medical school physicians in a teaching hospital in northern Italy, with a working population of 881 medical doctors. Data collection was performed using a structured form investigating clinical and epidemiological information. Results: One hundred sixty-two medical doctors contacted the Occupational Health Service reporting acute respiratory symptoms or close contact exposure to a confirmed COVID-19 case. Among the confirmed COVID-19 cases, most were male doctors during residency, and $85 \%$ presented a mild clinical picture. Fever $(70.3 \%)$ and cough $(51.4 \%)$ represented the most prevalent symptoms of COVID-19. As revealed by the univariate analysis, the prevalence of real-time reverse transcriptase-polymerase chain reaction (RT-PCR) positivity increased with age $(\mathrm{OR}=1.08,95 \% \mathrm{CI}: 1.02-1.14, \mathrm{p}=0.012)$, working in a COVID-19 ward $(\mathrm{OR}=3.33,95 \% \mathrm{CI}: 1.09-10.21$, $\mathrm{p}=0.031)$, presenting alteration or loss of smell/taste $(\mathrm{OR}=10.00,95 \% \mathrm{CI}: 2.80-35.69, \mathrm{p}<0.001)$ and myalgia $(\mathrm{OR}=3.20,95 \% \mathrm{CI}: 1.00-10.26$, $\mathrm{p}=0.046)$, while being a resident $(\mathrm{OR}=0.20,95 \% \mathrm{CI}: 0.05-0.80, \mathrm{p}=0.030)$ was associated with reduced odds of being infected, compared to staff physicians. Age and loss of smell/taste were the only factors independently associated with RT-PCR positivity. Conclusions: The majority of COVID-19 cases showed a mild
\end{abstract}

Received: October 20, 2020. Accepted: January 14, 2021.

Corresponding author: Paolo Durando, University of Genoa, Department of Health Sciences (DISSAL), Via A. Pastore 1,16132 Genoa, Italy (e-mail: durando@unige.it). 
clinical syndrome, ranging from absence or paucity of symptoms to common cold or influenza-like symptoms. The findings of the present study increase the accuracy of the clinical diagnosis for the prompt identification and management of suspected COVID-19 cases, being particularly useful during resurges of the SARS-CoV-2 pandemic. Int J Occup Med Environ Health. 2021;34(2):189-201

Key words:

occupational health, epidemiology, healthcare workers, clinical characteristics, COVID-19, SARS-CoV-2

\section{INTRODUCTION}

On December 31, 2019, China reported the first cases of atypical pneumonia in Wuhan, in the Hubei Province. Their etiological agent was subsequently identified as a new coronavirus, the seventh known to cause human disease, labelled as severe acute respiratory syndrome coronavirus 2 (SARS-CoV-2). This novel coronavirus quickly spread, resulting in an epidemic throughout China and in an increasing number of cases throughout the world. Europe was the first region to be affected by secondary cases of the SARS-CoV-2 disease (COVID-19) out of China [1]. On February 20, 2020, the first Italian case unrelated to China was reported in the Lombardy Region [2], followed by a rapid growth of localised clusters, reaching epidemic proportions observed nationwide, particularly in northern Italy. On March 11, 2020, the WHO declared the novel coronavirus outbreak a pandemic [3].

During the early stages of the epidemic, the Italian Ministry of Health recommended a suspected case definition of COVID-19 requiring the presence of both clinical symptoms (e.g., an acute respiratory infection, such as cough, fever or shortness of breath) and an epidemiological link (e.g., staying in areas of a presumed community transmission or having close contacts with COVID-19 cases) [4]. However, as a result of the nationwide community transmission, the criteria for the suspicion of COVID-19 changed over time, weighing more on clinical presentations. Occupational settings defined as essential services (e.g., the healthcare setting) experienced an increased risk of exposure to SARS-CoV-2 infections during the "lockdown period." According to the Occupational Safety and
Health Administration (OSHA) [5], healthcare workers (HCWs) are considered to have a very high risk of exposure to SARS-CoV-2. This, in turn, can cause workforce shortages, with potential implications on the overall function of healthcare systems [6].

During the current pandemic, occupational physicians worldwide have been dealing with an increasing number of workers infected with SARS-CoV-2, and have had to face difficult decision-making processes, balancing the implementation of preventive and protective measures, implications on fitness for work of both the potential or confirmed cases, and their return to work after recovery [7]. In the healthcare setting, the spread of infections can also cause staff shortages, which can result in the decreasing safety of the work environment for personnel as well as patient care.

In this scenario, especially in the most affected areas, residents were recruited to provide their assistance in caring for patients affected by COVID-19. Clinical diagnosis is not easy, particularly in mild cases. The current literature describes COVID-19 as an infectious disease with a broad clinical spectrum, ranging from pauci/asymptomatic upper respiratory tract infections (URTIs) to severe acute respiratory syndrome, sometimes accompanied by non-respiratory symptoms, causing complications including death. This poses challenges in the clinical differential diagnosis with other acute respiratory infections. To date, a large body of literature has been produced since the beginning of the outbreak, but there still remains a lack of knowledge regarding the typical clinical presentation of the disease, particularly for mild cases. The aim of the present study was to describe the prevalence of confirmed COVID-19 
cases in the study population, and the clinical characteristics and symptoms associated with the infection, and also to perform a sensitivity and specificity analysis of the associated clinical features, during the pandemic period.

\section{MATERIAL AND METHODS}

The present study was developed according to the Strengthening the Reporting of Observational Studies in Epidemiology (STROBE) reporting guideline [8].

\section{Study design and population}

An observational, cross-sectional study was performed using demographic, clinical, and laboratory data.

The study was carried out on March 6-May 19, 2020, during the first phase of the SARS-CoV-2 pandemic. It involved the medical school physicians and residents of the University of Genoa (a total workforce of 881 physicians, including 215 staff physicians and 666 resident doctors; age: $\mathrm{M} \pm \mathrm{SD} 35.63 \pm 11.54$; females: 48.8\%), employed at IRCCS Ospedale Policlinico San Martino of Genoa, Italy, the regional tertiary adult acute care reference hospital. The population routinely undergoes occupational health surveillance programs performed by the Occupational Health Service (OHS) in accordance with Italian Law [9].

During the pandemic period, HCWs with potential occupational exposure to SARS-CoV-2 were monitored for possible infections and the associated COVID-19 disease within a structured clinical epidemiological surveillance system. The surveillance system was activated through self-selection and reporting to the OHS ( $\mathrm{N}=162)$. Information concerning clinical epidemiological features and diagnostic tools for SARS-CoV-2 infections, together with ad hoc preventive and protective protocols and procedures, in accordance with the Ministry of Health's and regional policies, were developed, updated, and disseminated to all physicians and residents via the institutional intranet.
Subjects were classified as close contacts, suspected, probable or confirmed cases according to the Italian Ministry of Health's case definition [10]. All the HCWs within the study population who developed fever or any acute respiratory symptoms contacted the OHS and were included in the surveillance system for the adequate clinical and diagnostic management and follow-up. Upon being contacted by a HCW, the OHS personnel collected data concerning the exposure and clinical presentation. Symptomatic HCWs were tested for SARS-CoV-2 according to the following recommendations in effect: a nasopharyngeal (NP) swab was collected by a trained healthcare professional and the specimen was sent to the Reference Laboratory in the Liguria Region, in order to be analyzed through a semiquantitative real-time reverse transcriptase-polymerase chain reaction (RT-PCR).

Laboratory and clinical specimen collection procedures were performed in accordance with the Italian National Institute of Health (Istituto Superiore di Sanità) guidelines and the COVID-19 diagnosis was based on the WHO interim guidance [11]. All symptomatic HCWs were promptly removed from the work shift. Active monitoring was performed by the OHS through daily telephone interviews, filling the reported information in a structured case report form. Among those tested positive for SARS$\mathrm{CoV}-2$, recovery was defined as having 2 consecutive negative results of RT-PCR tests performed at least $24 \mathrm{~h}$ apart. The subjects that reported a close contact with a confirmed COVID-19 confirmed case were actively monitored daily for 14 days following the last exposure.

Staff including trained physicians of the OHS collected data and information from all the available standardized case report forms, concerning:

- exposure history to COVID-19 confirmed cases, both at the professional and community levels,

- acute symptoms (respiratory and non-respiratory),

- symptoms' characteristics (day of onset, duration),

- laboratory data (RT-PCR results). 
All other demographic information (e.g., age, gender, occupational category) was obtained with a backward review of the occupational medical records. All data for each person, except for symptoms' characteristics, were collected at $1 \mathrm{pt}$ in time, and were gathered in a dataset for statistical analysis. Information concerning the symptom onset and duration were collected during daily monitoring until complete clinical resolution.

The study was approved by the Ethics Committee of the Liguria Region (administrative reference number: 626/2020 ID 11073). All the activities were performed in compliance with the Declaration of Helsinki and current healthcare standards, according to the recommendations of the Italian Ministry of Health and WHO. All HCWs included in the survey signed written informed consent for SARS-CoV-2 testing and for data collection according to routine healthcare procedures of the Occupational Health Surveillance Program at IRCCS Ospedale Policlinico San Martino, Genoa, Italy. Data were anonymized before the analysis. Personal information regarding all the subjects included in the investigation was protected according to Italian law.

\section{Statistical analysis}

Continuous numerical variables were summarised as means and standard deviations (SDs) or, when appropriate, medians and interquartile ranges (IQRs). Nominal and ordinal categorical variables were summarized and described as frequency and percentages. The Mann-Whitney $\mathrm{U}$ test, the $\chi^{2}$ test, and Fisher's exact test were used, according to the variable type, for a univariate analysis of the association between professional and clinical characteristics and RT-PCR positivity, the main outcome of interest. Multivariate analyses were performed for variables with probability $(p)$ values of $<0.20$ in the univariate analysis. Differences were considered significant when $p<0.05$. A backward stepwise logistic regression was used to calculate the odds ratio (OR) and the $95 \%$ confidence intervals (CI). A 2-tailed $p<0.05$ was considered statistically significant. The sensitivity and specificity of different clinical criteria in the detection of RT-PCR positive cases were calculated using $2 \times 2$ contingency tables. All analyses were performed using SPSS statistical software v. 20.0 (IBM Corp.).

\section{RESULTS}

During the early phase of the SARS-CoV-2 epidemic at IRCCS Ospedale Policlinico San Martino of Genoa, 162 medical doctors contacted the OHS reporting acute respiratory symptoms $(\mathrm{N}=74,45.7 \%)$ or close contact exposure with a COVID-19 confirmed case $(\mathrm{N}=88,54.3 \%)$. The demographic characteristics, clinical features, and outcomes of the study population are summarized in Table 1. Considering all notifications, half were reported by female doctors; most of the reporting doctors were residents, and the mean age was in the fourth decade of life. Those that self-reported acute respiratory infection symptoms were classified as suspected, probable or confirmed cases. Among the confirmed COVID-19 cases, most were male doctors during residency; $85 \%$ had mild symptoms and were isolated at home; 3 subjects underwent hospitalization ( 2 subjects with respiratory distress signs and symptoms, and 1 with a skin rash on the upper and lower limbs); none was admitted to an intensive/subintensive care unit (ICU); and all the confirmed cases fully recovered.

Fever $(70.3 \%)$ and cough (51.4\%) represented the most prevalent symptoms overall. Other frequently reported symptoms, in the decreasing order, were runny nose (35.1\%), sore throat (28.4\%), alteration or loss of smell/taste $(27.0 \%)$, myalgia (25.7\%), followed by diarrhea (17.6\%), shortness of breath $(8.1 \%)$, and conjunctivitis (5.4\%). The prevalence of symptoms stratified by case definition can be found in Table 1. Overall, most of the reported exposures occurred in the occupational setting and, specifically, in non-COVID-19 wards; on the other hand, most confirmed cases (55\%) occurred in COVID-19 wards, albeit 
Table 1. Demographic characteristics, self-reported symptoms, and outcomes among medical school physicians and residents employed at IRCCS Ospedale Policlinico San Martino of Genoa, Italy, reporting acute symptoms suspected of COVID-19 or close contact exposure to a confirmed COVID-19 case, in March 6-May 19, 2020, during the first phase of the SARS-CoV-2 pandemic, referring to the Occupational Health Service of the University of Genoa

\begin{tabular}{|c|c|c|c|c|c|}
\hline \multirow[b]{2}{*}{ Variable } & \multicolumn{5}{|c|}{$\begin{array}{c}\text { Participants } \\
(\mathrm{N}=162)\end{array}$} \\
\hline & total & $\begin{array}{c}\text { confirmed } \\
\text { COVID-19 } \\
\text { cases } \\
(\mathrm{N}=20)\end{array}$ & $\begin{array}{l}\text { negative cases } \\
\qquad(\mathrm{N}=41)\end{array}$ & $\begin{array}{l}\text { probable cases } \\
\qquad(\mathrm{N}=13)\end{array}$ & $\begin{array}{l}\text { close contact } \\
\quad(\mathrm{N}=88)\end{array}$ \\
\hline \multicolumn{6}{|l|}{ Demographic characteristics } \\
\hline male $[\mathrm{n}(\%)]$ & $81(50.0)$ & $12(60.0)$ & $15(36.6)$ & $6(46.2)$ & $48(54.5)$ \\
\hline female $[\mathrm{n}(\%)]$ & $81(50.0)$ & $8(40.0)$ & $26(63.4)$ & $7(53.8)$ & $40(45.5)$ \\
\hline age [years] $(\mathrm{M} \pm \mathrm{SD})$ & $32.8 \pm 9.0$ & $39.4 \pm 14.1$ & $31.5 \pm 6.9$ & $29.5 \pm 4.9$ & $32.4 \pm 8.3$ \\
\hline \multicolumn{6}{|l|}{ Work category $[\mathrm{n}(\%)]$} \\
\hline staff physicians & $24(14.8)$ & $7(35.0)$ & $4(9.8)$ & $1(7.7)$ & $12(13.6)$ \\
\hline residents & $138(85.2)$ & $13(65.0)$ & $37(90.2)$ & $12(92.3)$ & $76(86.4)$ \\
\hline \multicolumn{6}{|l|}{ Self-reported symptoms [n (\%)] } \\
\hline fever $^{\mathrm{a}}$ & - & $14(70.0)$ & $29(70.7)$ & $9(69.2)$ & - \\
\hline cough & - & $12(60.0)$ & $17(41.5)$ & $9(69.2)$ & - \\
\hline shortness of breath & - & $2(10.0)$ & $4(9.8)$ & $0(0.0)$ & - \\
\hline runny nose & - & $8(40.0)$ & $16(39.0)$ & $2(15.4)$ & - \\
\hline sore throat & - & $5(25.0)$ & $16(39.0)$ & $0(0.0)$ & - \\
\hline alteration or loss of smell/taste & - & $12(60.0)$ & $6(14.6)$ & $2(15.4)$ & - \\
\hline myalgia & - & $9(45.0)$ & $9(22.0)$ & $1(7.7)$ & - \\
\hline diarrhea & - & $2(10.0)$ & $10(24.4)$ & $1(7.7)$ & - \\
\hline conjunctivitis & - & $1(5.0)$ & $3(7.3)$ & $0(0.0)$ & - \\
\hline \multicolumn{6}{|c|}{ Self-reported place of exposure ${ }^{\mathrm{b}}[\mathrm{n}(\%)]$} \\
\hline workplace & $127(90.1)$ & $13(81.3)$ & $26(92.9)$ & $47(87.0)^{\mathrm{c}}$ & $81(92.0)$ \\
\hline other than workplace & $14(9.9)$ & $3(18.7)$ & $2(7.1)$ & $7(13.0)^{\mathrm{c}}$ & $7(8.0)$ \\
\hline \multicolumn{6}{|l|}{ Occupational setting [n (\%)] } \\
\hline non-COVID-19 ward & $104(64.2)$ & $9(45.0)$ & $30(73.2)$ & $45(60.8)^{c}$ & $59(67.0)$ \\
\hline COVID-19 ward & $58(35.8)$ & $11(55.0)$ & $11(26.8)$ & $29(39.2)^{c}$ & $29(33.0)$ \\
\hline \multicolumn{6}{|c|}{ Clinical outcomes of confirmed cases [n $(\%)]$} \\
\hline non-hospitalized & - & $17(85.0)$ & - & - & - \\
\hline hospitalized & - & $3(15.0)$ & - & - & - \\
\hline
\end{tabular}

a Fever was defined as a body temperature $\geq 37.5^{\circ} \mathrm{C}$.

${ }^{\mathrm{b}}$ Reported results based on available data.

${ }^{\mathrm{c}}$ Comprehensive data of overall case notifications (confirmed, probable and negative). 


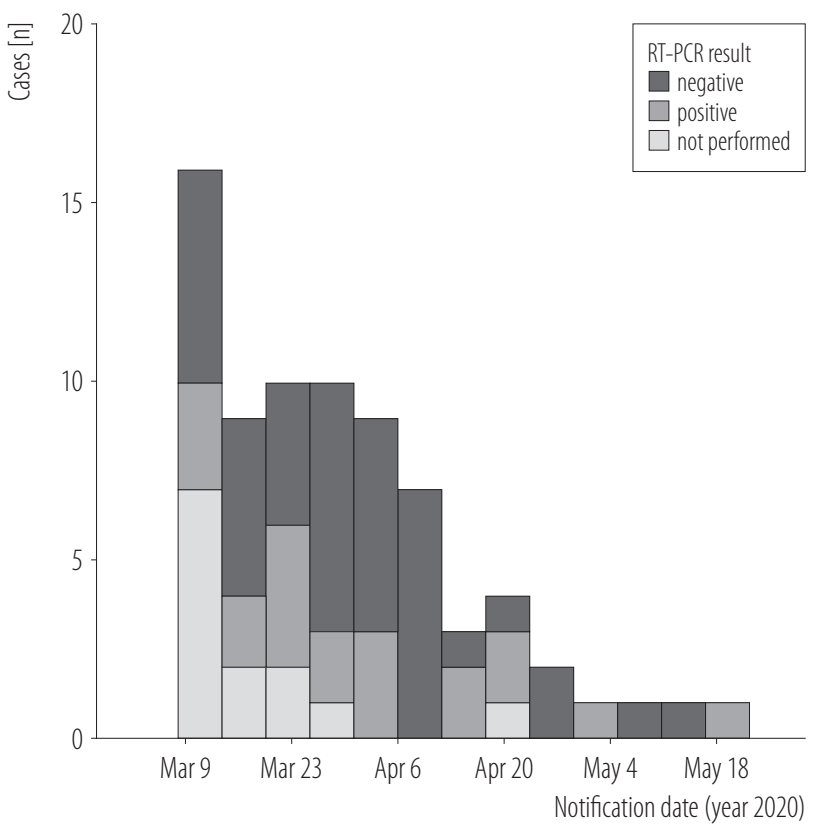

Figure 1. Case notifications $(\mathrm{N}=74)$ to the Occupational Health Service during the study period, stratified according to SARS-CoV-2 real-time reverse transcriptase-polymerase chain reaction (RT-PCR) test results, whenever performed

no significant difference emerged comparing COVID-19 to non-COVID-19 areas $\left(\chi^{2}=2.875, \mathrm{p}=0.09\right)$.

The number of reported incident cases of acute respiratory infections was the highest soon after the start of the monitoring, followed by a progressive reduction in the following 2 months (Figure 1).

Among the subjects who had undergone a NP swab with subsequent RT-PCR testing ( $\mathrm{N}=61$ ), no statistical difference was shown between negative RT-PCR acute respiratory infection cases and confirmed COVID-19 cases with respect to the specific symptom duration and symptom onset after the last known exposure (Figure 2). In both groups, sore throat, cough and loss of smell/taste were the first symptoms to appear, with the latter 2 lasting the longest. Diarrhea showed a late onset in both groups, appearing after over a week following the exposure.

Univariate and multivariate analyses of the variables associated with RT-PCR positivity are outlined in Table 2. As revealed by the univariate analysis, the prevalence of
RT-PCR positivity increased with several demographic and occupational characteristics such as age $(\mathrm{OR}=1.08$, 95\% CI: $1.02-1.14, p=0.012)$, working in a COVID-19 ward (OR $=3.33,95 \% \mathrm{CI}: 1.09-10.21, \mathrm{p}=0.031)$, as well as having specific clinical manifestations such as alteration or loss of smell/taste (OR $=10.00,95 \%$ CI: $2.80-35.69$, $\mathrm{p}<0.001)$ and myalgia $(\mathrm{OR}=3.20,95 \%$ CI: $1.00-10.26$, $\mathrm{p}=0.046)$. Moreover, compared to staff physicians, residents showed reduced odds of infection with SARS-CoV-2 $(\mathrm{OR}=0.20,95 \% \mathrm{CI}: 0.05-0.80, \mathrm{p}=0.030)$. The multivariate logistic regression model resulted in age $(\mathrm{OR}=1.13$, 95\% CI: $1.04-1.23, \mathrm{p}=0.003)$ and alteration or loss of smell/taste $(\mathrm{OR}=26.63,95 \%$ CI: 5.03-141.06, $\mathrm{p}<0.001)$ being the only factors independently associated with a confirmed COVID-19 case.

With respect to the diagnostic accuracy of the clinical criteria in the identification of COVID-19 cases (Table 3), the highest sensitivity was revealed for fever, albeit with an insufficient specificity. The presence of dyspnoea, cough, myalgia and runny nose showed improved specificity. The combination of loss of smell/taste with at least 1 of the symptoms initially indicated by the Ministry of Health (fever, cough, dyspnoea) provided a $15 \%$ sensitivity improvement.

\section{DISCUSSION}

To the best of the authors' knowledge, this study represents the first assessment of COVID-19 clinical and epidemiological features involving young medical doctors. Indeed, the present study found that medical school physicians and residents of a large teaching reference hospital located in the Liguria Region, the fourth most affected area in Italy [12], were involved in the first epidemic wave, developing mostly mild clinical syndromes, all resolving with a rapid and benign course. The appropriate occupational management of this work category, largely employed on the frontline during the pandemic, represented a unique challenge for stopping the nosocomial spread of the infection among colleagues and patients, due to the high pro- 

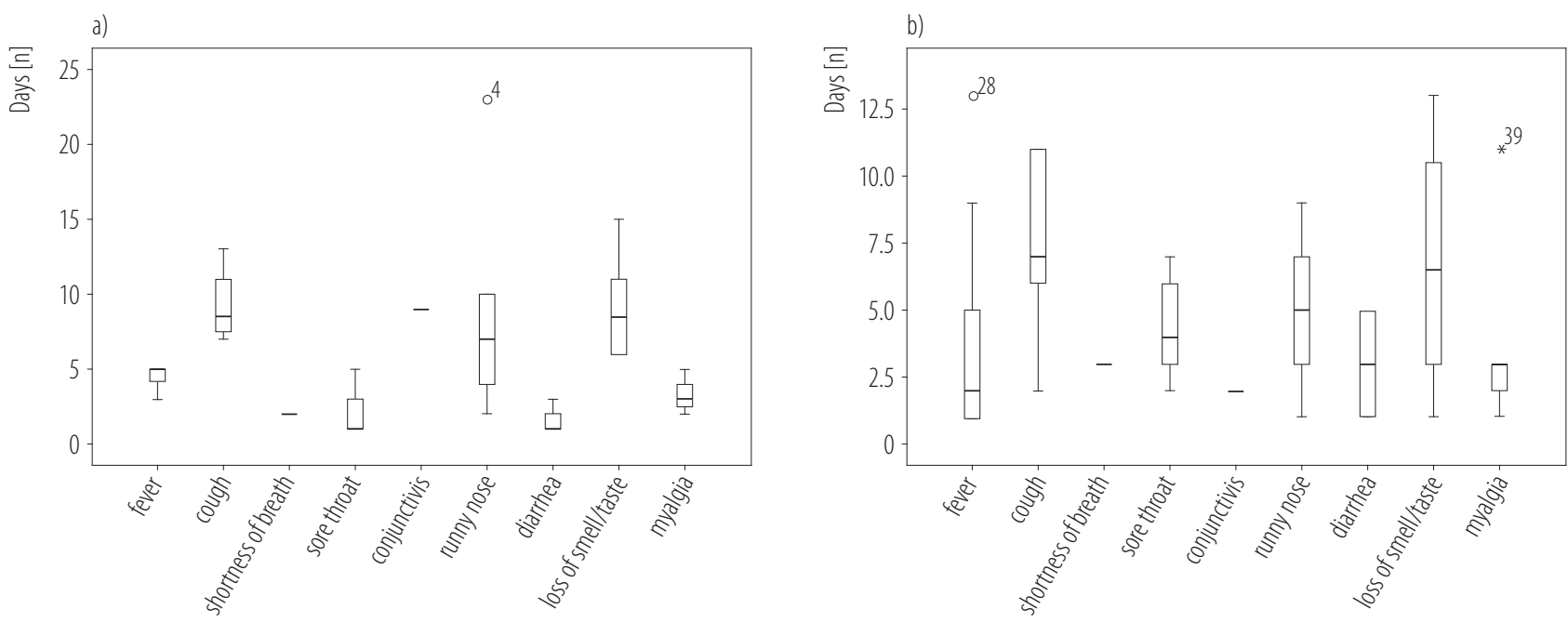

Symptom

Symptom
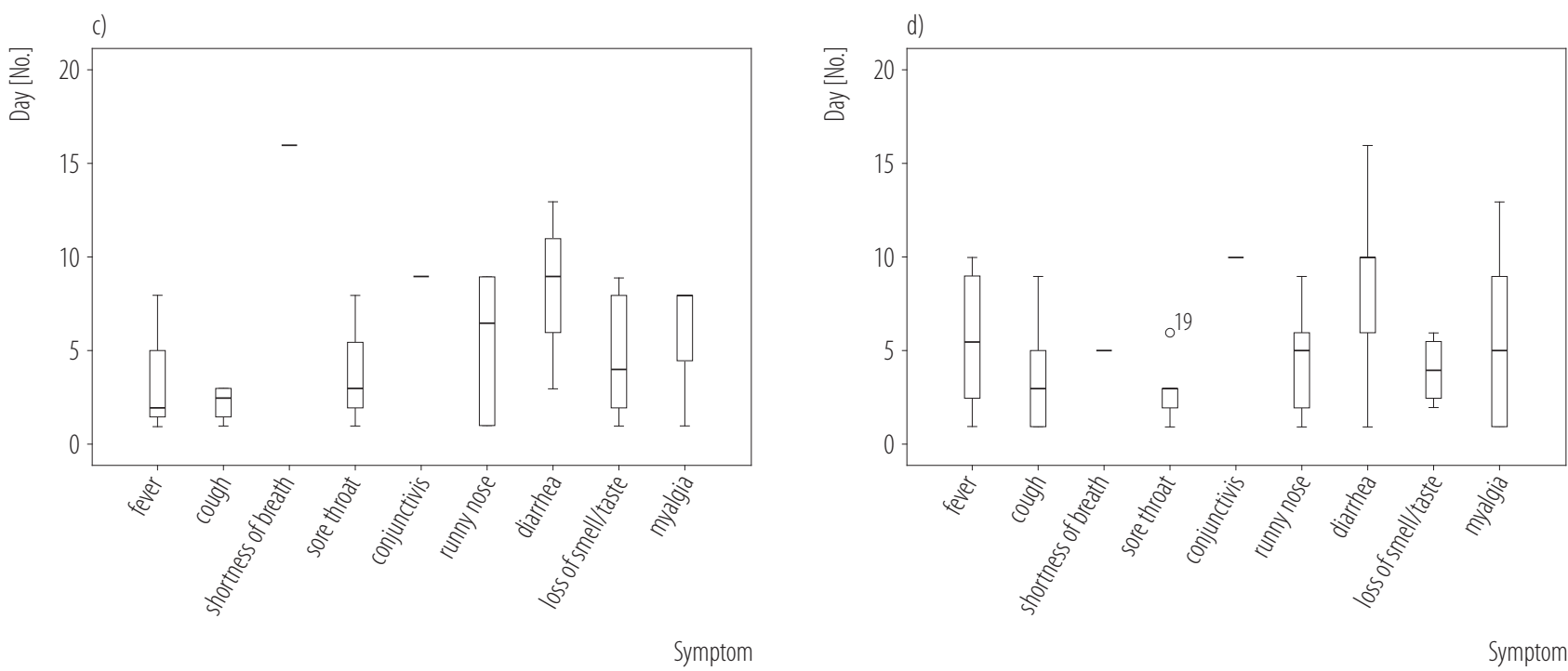

Symptom

Data given as median days and interquartile range.

Isolated points on some boxplots indicate outliers, with the corresponding subject labels: ${ }^{\circ}$ outlier at least $1.5 \times$ interquartile range $(\mathrm{IQR})$ from the median; * extreme outliers at least 3.0 $\times$ IQR from the median. The width of the box defines IQR (IQR = Q3-Q1).

The whiskers show the range of the values outside IQR within the $1.5 \times$ IQR limit.

Figure 2. Duration of symptoms (a and b), and time of symptoms onset since exposure (c and d) - between confirmed COVID-19 cases (a and c), and in acute respiratory infection cases with a negative SARS-CoV-2 real-time reverse transcriptase-polymerase chain reaction (RT-PCR) test result ( $b$ and d)

portion of asymptomatic and pauci-symptomatic clinical presentations among young adults [13]. During the study period, almost $3 \%$ of the study population was affected by COVID-19, mostly reporting an exposure in the occupational setting, particularly in COVID-19 wards.
Indeed, in the most affected countries, the current pandemic has largely involved healthcare workers. In Europe, the European Centre for Disease Prevention and Control determined the overall percentage of HCWs among COVID-19 cases in May at $23.2 \%$ [14] while in Italy it was reported to 
Table 2. Univariate and multivariate analyses of demographic, professional and clinical characteristics associated with SARS-CoV-2 real-time reverse transcriptase-polymerase chain reaction (RT-PCR) positivity in a cohort of medical school physicians and residents employed at IRCCS Ospedale Policlinico San Martino of Genoa, Italy, reporting acute respiratory symptoms suspected for COVID-19 or close contact exposure to a COVID-19 confirmed case, in March 6-May 19, 2020, during the first phase of the SARS-CoV-2 pandemic, referring to the Occupational Health Service of the University of Genoa

\begin{tabular}{|c|c|c|c|c|c|c|}
\hline \multirow[t]{2}{*}{ Variable } & \multicolumn{2}{|c|}{$\begin{array}{l}\text { Participants reporting acute } \\
\text { respiratory symptoms who } \\
\text { underwent RT-PCR testing } \\
\qquad(\mathrm{N}=61)\end{array}$} & \multicolumn{2}{|c|}{ Univariate analysis } & \multicolumn{2}{|c|}{ Multivariate analysis } \\
\hline & $\begin{array}{c}\text { total } \\
{[\mathrm{n}]}\end{array}$ & $\begin{array}{c}\text { RT-PCR positivity } \\
{[\mathrm{n}(\%)]}\end{array}$ & OR $(95 \% \mathrm{CI})$ & $\mathrm{p}$ & OR $(95 \% \mathrm{CI})$ & $\mathrm{p}$ \\
\hline Age (per 1 year increase) & & & $1.08(1.02-1.14)$ & 0.012 & $1.13(1.04-1.23)$ & 0.003 \\
\hline \multicolumn{7}{|l|}{ Gender } \\
\hline female & 34 & $8(23.5)$ & ref. & & & \\
\hline male & 27 & $12(44.4)$ & $2.60(0.87-7.79)$ & 0.084 & & \\
\hline \multicolumn{7}{|l|}{ Work category } \\
\hline staff physicians & 11 & $7(63.6)$ & ref. & & & \\
\hline residents & 50 & $13(26.0)$ & $0.20(0.05-0.80)$ & $0.030^{\mathrm{b}}$ & & \\
\hline \multicolumn{7}{|l|}{ Ward } \\
\hline non-COVID-19 & 39 & $9(23.1)$ & ref. & & & \\
\hline COVID-19 & 22 & $11(50.0)$ & $3.33(1.09-10.21)$ & 0.031 & & \\
\hline \multicolumn{7}{|c|}{ Self-reported place of exposure ${ }^{a}$} \\
\hline other than workplace & 5 & $3(60.0)$ & ref. & & & \\
\hline workplace & 39 & $13(33.3)$ & $0.33(0.05-2.25)$ & $0.336^{\mathrm{b}}$ & & \\
\hline \multicolumn{7}{|l|}{ Self-reported symptoms ${ }^{\mathrm{a}}$} \\
\hline \multicolumn{7}{|l|}{ fever } \\
\hline no & 18 & $6(33.3)$ & ref. & & & \\
\hline yes & 43 & $14(32.6)$ & $0.97(0.30-3.11)$ & 0.953 & & \\
\hline \multicolumn{7}{|l|}{ cough } \\
\hline no & 32 & $8(25.0)$ & ref. & & & \\
\hline yes & 29 & $12(41.4)$ & $2.12(0.71-6.29)$ & 0.174 & & \\
\hline \multicolumn{7}{|l|}{ runny nose } \\
\hline no & 36 & $11(30.6)$ & ref. & & & \\
\hline yes & 24 & $8(33.3)$ & $1.14(0.38-3.43)$ & 0.821 & & \\
\hline \multicolumn{7}{|l|}{ sore throat } \\
\hline no & 39 & $14(35.9)$ & ref. & & & \\
\hline yes & 21 & $5(23.8)$ & $0.56(0.17-1.85)$ & 0.337 & & \\
\hline \multicolumn{7}{|c|}{ alteration or loss of smell/taste } \\
\hline no & 42 & $7(16.7)$ & ref. & & & \\
\hline yes & 18 & $12(66.7)$ & $10.00(2.80-35.69)$ & 0.000 & $26.63(5.03-141.06)$ & 0.000 \\
\hline
\end{tabular}


Table 2. Univariate and multivariate analyses of demographic, professional and clinical characteristics associated with SARS-CoV-2 real-time reverse transcriptase-polymerase chain reaction (RT-PCR) positivity in a cohort of medical school physicians and residents employed at IRCCS Ospedale Policlinico San Martino of Genoa, Italy, reporting acute respiratory symptoms suspected for COVID-19 or close contact exposure to a COVID-19 confirmed case, in March 6-May 19, 2020, during the first phase of the SARS-CoV-2 pandemic, referring to the Occupational Health Service of the University of Genoa - cont.

\begin{tabular}{|c|c|c|c|c|c|c|}
\hline \multirow[t]{2}{*}{ Variable } & \multicolumn{2}{|c|}{$\begin{array}{l}\text { Participants reporting acute } \\
\text { respiratory symptoms who } \\
\text { underwent RT-PCR testing } \\
\qquad(\mathrm{N}=61)\end{array}$} & \multicolumn{2}{|c|}{ Univariate analysis } & \multicolumn{2}{|c|}{ Multivariate analysis } \\
\hline & $\begin{array}{c}\text { total } \\
{[\mathrm{n}]}\end{array}$ & $\begin{array}{l}\text { RT-PCR positivity } \\
{[\mathrm{n}(\%)]}\end{array}$ & OR $(95 \% \mathrm{CI})$ & $\mathrm{p}$ & OR $(95 \% \mathrm{CI})$ & $\mathrm{p}$ \\
\hline \multicolumn{7}{|c|}{$\begin{array}{l}\text { Self-reported symptoms }{ }^{\mathrm{a}} \text { - cont. } \\
\text { myalgia }\end{array}$} \\
\hline no & 42 & $10(23.8)$ & ref. & & & \\
\hline yes & 18 & $9(50.0)$ & $3.20(1.00-10.26)$ & 0.046 & & \\
\hline \multicolumn{7}{|l|}{ diarrhea } \\
\hline no & 48 & $17(35.4)$ & ref. & & & \\
\hline yes & 12 & $2(16.7)$ & $0.37(0.07-1.86)$ & $0.306^{\mathrm{b}}$ & & \\
\hline \multicolumn{7}{|l|}{ shortness of breath } \\
\hline no & 55 & $18(32.7)$ & ref. & & & \\
\hline yes & 6 & $2(33.3)$ & $1.03(0.17-6.15)$ & $1.000^{\mathrm{b}}$ & & \\
\hline \multicolumn{7}{|l|}{ conjunctivitis } \\
\hline no & 56 & $18(32.1)$ & ref. & & & \\
\hline yes & 4 & $1(25.0)$ & $0.70(0.07-7.24)$ & $1.000^{\mathrm{b}}$ & & \\
\hline
\end{tabular}

${ }^{\text {a }}$ Reported results based on available data.

${ }^{\mathrm{b}}$ Fisher's exact test.

be $12.2 \%$ [12]. However, updated information is not always available, and data are often vastly variable between studies and countries depending on the timing of data collection in relation to the stage of the outbreak at the country level: in the USA data until April showed 3\% of infections among HCWs, while in China it was $3.8 \%$ until February $[15,16]$. Upon the activation of the hospital surveillance system, a peak of case notifications was recorded, with subsequent reductions in reporting during the epidemic. This could have been caused by several factors, such as a generally higher circulation of the virus at the community level, as well as due to structural issues occurring in the occupational setting: at the beginning of the pandemic, difficulties in the implementation of effective infection preven- tion and control (IPC) protocols, caused by the rapidly evolving epidemic scenario, with subsequent shortages in personal protective equipment, particularly FFP2 respirators and gown supplies and sanitizers, might have contributed to the increased risk of infections among HCWs [17]. Over time, a slowdown in the infection rates at the community level was obtained through public health policies, and improvements in IPC measures were also reflected in case notifications in the population (Figure 1). Case finding and management procedures with the subsequent tracing of contacts were performed, setting by setting, based on SARS-CoV-2 RT-PCR testing with priority in suspected cases that were identified through an accurate surveillance of clinical signs and symptoms. 
Table 3. Accuracy of clinical criteria in the identification of COVID-19 cases

\begin{tabular}{lcc}
\hline \multicolumn{1}{c}{ Symptom } & $\begin{array}{c}\text { Sensitivity } \\
{[\%(95 \mathrm{CI})]}\end{array}$ & $\begin{array}{c}\text { Specificity } \\
{[\%(95 \mathrm{CI})]}\end{array}$ \\
\hline Fever & $70.0(45.7-88.1)$ & $29.3(16.1-45.5)$ \\
Cough & $60.0(36.1-80.9)$ & $58.5(42.1-73.7)$ \\
Shortness of breath & $10.0(1.2-31.7)$ & $90.2(76.9-97.3)$ \\
Sore throat & $26.3(9.2-51.2)$ & $61.0(44.5-75.8)$ \\
Conjunctivitis & $5.3(0.1-26.0)$ & $92.7(80.1-98.5)$ \\
Runny nose & $42.1(20.3-66.5)$ & $61.0(44.5-75.8)$ \\
Diarrhea & $10.5(1.3-33.1)$ & $75.6(59.7-87.6)$ \\
Loss of smell/taste & $63.2(38.4-83.7)$ & $85.4(70.8-94.4)$ \\
Myalgia & $47.4(24.5-71.1)$ & $78.0(62.4-89.4)$ \\
Two associated symptoms & & \\
$\quad$ from among fever, cough, dyspnoea & & $70.7(54.5-83.9)$ \\
from among fever, cough, dyspnoea and loss of smell/taste & $55.0(31.5-76.9)$ & $70.7(54.5-83.9)$ \\
\hline
\end{tabular}

Interestingly, notified exposures which occurred among residents were found to be less likely associated with developing COVID-19 compared to staff physicians. This could be explained by the fact that staff physicians performed higher risk procedures such as aerosol generating procedures or faced higher intensity exposures more frequently. Residents may have been more sensitive in the self-notification of symptoms, while only staff physicians with important exposures or symptoms may have sought information for testing.

In the present study, the most prevalent symptoms among COVID-19 cases were not different compared to other URTI cases that resulted negative in SARS-CoV-2 RT-PCR. Two clinical features, myalgia and anosmia/dysgeusia, were found to be associated positively with COVID-19, with the latter showing an independent association with the infection at the multivariate analysis, although with very wide CIs. Indeed, while myalgia is considered a non-specific symptom of many inflammatory disorders, the sudden loss of smell is considered to be, among infectious causes, more frequently caused by pathogens infecting the respiratory and olfactory mucosa [18]. However, the specificity of this symptom is still debated in scientific literature: although some authors have suggested this symptom to be specific to a SARS-CoV-2 infection [19], some even advocating a possible neurological or sensorineural infection pathway [20], post-viral olfactory loss has previously been associated with many known pathogens, including rhinoviruses and endemic coronaviruses [21].

Based on recent evidence on the frequency of olfactory loss as a reported or measured clinical feature in COVID-19 cases [22], the main international and national public health agencies introduced this symptom in the clinical criteria of COVID-19 case definitions [23,24]. This was also reflected in the Italian population where, by the addition of anosmia to the clinical criteria, an improvement in the detection of cases equal to $15 \%$ in sensitivity was demonstrated. Moreover, cough and anosmia were most often the first symptoms to appear, and the last to disappear, without a statistically significant difference among COVID-19 and other URTI cases. Indeed, it is recognized that these 2 symptoms can often persist long after the disease has resolved $[25,26]$, with some authors reporting their presence months after clinical recovery among severe cases [27]. In the present study, however, these symptoms resolved completely in a median time of approx. 9 days. Overall, in the studied population of mostly young workers, the majority of cases showed a mild clinical syndrome, 
ranging from the absence or paucity of symptoms to common cold or influenza-like symptoms, and recovered at home without hospitalization.

The positive association between the increasing age and COVID-19 clinical presentation has already been described in literature [28]. The broad clinical spectrum of COVID-19 is confirmed in the present study: with a significant implication for the early identification of COVID-19 cases and contact tracing in view of the possible future epidemic waves: this is valid particularly in mild and atypical cases that could act as an undetected source of infection [29]. Moreover, this study provides some useful insights for occupational health and public health professionals, particularly for general practitioners, policy makers and health authorities facing the current emergency scenario.

It is noteworthy that during the study period many reported URTI cases were not caused by SARS-CoV-2 but by other pathogens. This highlights the fact that SARS-CoV-2 only adds up to an already important burden of acute respiratory infections, present both in the occupational and community settings. In this regard, the non-specificity of clinical characteristics in mild cases is a crucial factor that must be taken into account in order to implement adequate IPC measures, including personal and collective protective equipment and vaccinations against other vaccine-preventable respiratory disease (e.g., during the next flu season). The description and analysis of the clinical patterns among infected workers provides further data on the different ranges of possible presentations, particularly among those with a mild syndrome, increasing the understanding of this disease. The findings of the study are in line with the current literature, and although based on a small population, they are strengthened by the application of a rigorous methodological approach.

However, this study is limited in some respects, particularly due to the self-notification and reporting of data, with the possible introduction of selection and recall bias, as well as a lack of effective and precise exposure assessment.
Indeed, the possibility of overestimation/underestimation of some particular clinical features due to a still imprecise knowledge of COVID-19 during the first weeks of the pandemic [30] cannot be ruled out. At that time, most of the research focused on the description and analysis of more severe COVID-19 cases, increasing the awareness of more severe symptoms, while milder clinical aspects might have been overlooked by patients as non-relevant or not compatible with a SARS-CoV-2 infection.

Moreover, the limited number and homogeneity among individual cases might include some confounders that could not be factored into the analysis. Indeed, at the multivariate analysis, the independent associations found showed a very wide $\mathrm{CI}$, reflecting this limitation. Finally, case inclusion and testing criteria were limited in line with the Italian Health Ministry's suspected case definition requiring the presence of symptoms, likely resulting in omitting several asymptomatic or pauci-symptomatic cases, thus making any precise epidemiological inference improbable. Therefore, the findings of the present study should be interpreted in light of these limitations. High quality research is required in order to confirm the validity of these findings, and to better define the range and frequency of clinical presentations in various degrees of the COVID-19 disease severity, as well as to evaluate the true risk of the infection transmission by asymptomatic cases.

\section{CONCLUSIONS}

Since early 2020, occupational health professionals, as well as all other HCWs, have faced an unprecedented health emergency. These findings contribute to improving the knowledge on the epidemiological and clinical features of COVID-19 and other acute respiratory infections in a cohort of young HCWs employed during the spread of the SARS-CoV-2 pandemic in Italy, providing some meaningful insights for the rapid identification and proper management of suspected COVID-19 cases in the event of a possible re-emergence of the outbreak. This may bring 
benefits in terms of both protection for healthcare workers, and infection prevention and control in the healthcare setting.

In this regard, the employment and appropriate occupational management of medical school residents, who faced the early stage of the pandemic in the most affected areas in Italy, represented a unique challenge for reducing the health burden of the nosocomial spread of SARS$\mathrm{CoV}-2$ infections among colleagues and patients. During the next autumn season, it will be useful to consider any acute respiratory infection eligible for SARS-CoV-2 RT-PCR testing, also in young workers with mild clinical features that could represent a source of unrecognized transmission for co-workers and patients in the healthcare setting. In this scenario, flu vaccination is again highly recommended for this work category.

\section{ACKNOWLEDGMENTS}

Methodological and statistical advice was provided by Alessio Signori, Ph.D., Assistant Professor in Medical Statistics, Department of Health Sciences, Biostatistics Section, University of Genoa.

\section{REFERENCES}

1. European Centre for Disease Prevention and Control. Outbreak of severe acute respiratory syndrome coronavirus 2 (SARS-CoV-2): increased transmission beyond China-fourth update, 14 February 2020 [Internet]. Stockholm: The Centre; 2020 [cited 2020 Oct 10]. Available from: https://www.ecdc. europa.eu/sites/default/files/documents/SARS-CoV-2-riskassessment-14-feb-2020.pdf.

2. Livingston E, Bucher K. Coronavirus Disease 2019 (COVID-19) in Italy. JAMA. 2020;323(14):1335, https://doi.org/ 10.1001/jama.2020.4344.

3. Cucinotta D, Vanelli M. WHO Declares COVID-19 a Pandemic. Acta Biomed. 2020;91(1):157-60, https://doi.org/10. 23750/abm.v91i1.9397.

4. [Italian Ministry of Health. Circular n. 6360 on 27/02/2020 "COVID-19 - Update”]. Italian.
5. Occupational Safety and Health Administration. Coronavirus: Guidance on Preparing Workplaces for COVID-19 [Internet]. Washington, DC: The Administration; 2020 [cited 2020 Oct 10]. Available from: https://www.osha.gov/Publications/OSHA3990.pdf.

6. Bielicki JA, Duval X, Gobat N, Goossens H, Koopmans M, Tacconelli E, et al. Monitoring approaches for health-care workers during the COVID-19 pandemic. Lancet Infect Dis. 2020;20(10): e261-7, https://doi.org/10.1016/S1473-3099(20)30458-8.

7. Mutti A. Occupational Medicine in the time of COVID-19. Med Lav. 2020;111(2):83-6, https://doi.org/10.23749/mdl.v11 $1 \mathrm{i} 2.9546$.

8. Von Elm E, Altman DG, Egger M, Pocock SJ, Gøtzsche PC, Vandenbroucke JP. The Strengthening the Reporting of Observational Studies in Epidemiology (STROBE) statement: guidelines for reporting observational studies. Lancet. 2007;370(9596):1453-7,https://doi.org/10.1016/S0140-6736(07) 61602-X.

9. [Legislative Decree 9 April 2008, no. 81. Italian law on safety and health at work. G.U. n. 101, 30 Apr 2008 Suppl. n. 108; G.U. n. 1805 Aug 2009 Suppl. n. 142/L]. Italian.

10. [Italian Ministry of Health. Circular n. 7922 on 09/03/2020 "COVID-19. Updated case definition"]. Italian.

11. World Health Organization. Laboratory testing for coronavirus disease 2019 (COVID-19) in suspected human cases: Interim guidance - 19 March 2020 [Internet]. Geneva: The Organization; 2020 [cited 2020 Oct 10]. Available from: https:// www.who.int/publications-detail/10665-331501.

12. Istituto Superiore di Sanità. COVID-19 epidemic: 14 July 2020 national update [Internet]. Rome: The Instituto; 2020 [cited 2020 Oct 10]. Available from: https://www.epicentro. iss.it/coronavirus/bollettino/Bollettino-sorveglianza-integrata-COVID-19_14-luglio-2020.pdf.

13. Treibel TA, Manisty C, Burton M, McKnight Á, Lambourne J, Augusto JB, et al. COVID-19: PCR screening of asymptomatic health-care workers at London hospital. Lancet. 2020;395(10237):1608-10, https://doi.org/10.1016/S0140-67 36(20)31100-4. 
14. European Centre for Disease Prevention and Control [Internet]. Solna: The Centre; 2020 [cited 2020 Oct 10]. Epidemiology of COVID-19. Available from: https://www.ecdc. europa.eu/en/covid-19/latest-evidence/epidemiology.

15. CDC COVID-19 Response Team. Characteristics of Health Care Personnel with COVID-19 - United States, February 12 April 9, 2020. MMWR Morb Mortal Wkly Rep. 2020;69(15):477-81, https://doi.org/10.15585/mmwr.mm6915e6.

16. Wu Z, McGoogan JM. Characteristics of and Important Lessons From the Coronavirus Disease 2019 (COVID-19) Outbreak in China: Summary of a Report of 72314 Cases From the Chinese Center for Disease Control and Prevention. JAMA. 2020;323(13):1239-42, https://doi.org/10.1001/jama.2020.2648.

17. Ranney ML, Griffeth V, Jha AK. Critical Supply Shortages - The Need for Ventilators and Personal Protective Equipment during the Covid-19 Pandemic. N Engl J Med. 2020;382(18):e41, https://doi.org/10.1056/NEJMp2006141.

18. Boesveldt S, Postma EM, Boak D, Welge-Luessen A, Schöpf V, Mainland JD, et al. Anosmia-A Clinical Review. Chem Senses. 2017;42(7):513-23, https://doi.org/10.1093/chemse/ bjx025.

19. Brann DH, Tsukahara T, Weinreb C, Lipovsek M, Van den Berge K, Gong B, et al. Non-neuronal expression of SARS$\mathrm{CoV}-2$ entry genes in the olfactory system suggests mechanisms underlying COVID-19-associated anosmia. Sci Adv. 2020;6(31):eabc5801, https://doi.org/10.1126/sciadv.abc5801.

20. Ellul MA, Benjamin L, Singh B, Lant S, Michael BD, Easton A, et al. Neurological associations of COVID-19. Lancet Neurol. 2020;19(9):767-83, https://doi.org/10.1016/ S1474-4422(20)30221-0.

21. Suzuki M, Saito K, Min WP, Vladau C, Toida K, Itoh H, et al. Identification of viruses in patients with postviral olfactory dysfunction. Laryngoscope. 2007;117(2):272-7, https://doi. org/10.1097/01.mlg.0000249922.37381.1e.

22. Mercante G, Ferreli F, De Virgilio A, Gaino F, Di Bari M, Colombo G, et al. Prevalence of Taste and Smell Dysfunction in Coronavirus Disease 2019. JAMA Otolaryngol Head Neck Surg. 2020;146(8):1-6, https://doi.org/10.1001/jamaoto.2020.1155.

23. European Centre for Disease Prevention and Control [Internet]. Solna: The Centre; 2020 [cited 2020 Oct 10]. Case definition for coronavirus disease 2019 (COVID-19), as of 29 May 2020. Available from: https://www.ecdc.europa.eu/ en/covid-19/surveillance/case-definition.

24. Centers for Disease Control and Prevention [Internet]. Atlanta: The Centers; 2020 [cited 2020 Oct 10]. Symptoms of Coronavirus. Available from: https://www.cdc.gov/corona virus/2019-ncov/symptoms-testing/symptoms.html.

25. Braman SS. Chronic cough due to chronic bronchitis: ACCP evidence-based clinical practice guidelines. Chest. 2006;129(1 Suppl):104S-15S, https://doi.org/10.1378/chest. 129.1_suppl.104S.

26. Lee DY, Lee WH, Wee JH, Kim JW. Prognosis of postviral olfactory loss: follow-up study for longer than one year. Am J Rhinol Allergy. 2014;28(5):419-22, https://doi.org/10.2500/ ajra.2014.28.4102.

27. Carfì A, Bernabei R, Landi F. Persistent Symptoms in Patients After Acute COVID-19. JAMA. 2020;324(6):603-5, https://doi.org/10.1001/jama.2020.12603.

28. Liu Y, Mao B, Liang S, Yang JW, Lu HW, Chai YH, et al. Association between age and clinical characteristics and outcomes of COVID-19. Eur Respir J. 2020;55(5):2001112, https://doi.org/10.1183/13993003.01112-2020.

29. Furukawa NW, Brooks JT, Sobel J. Evidence Supporting Transmission of Severe Acute Respiratory Syndrome Coronavirus 2 While Presymptomatic or Asymptomatic. Emerg Infect Dis. 2020;26(7):e201595, https://doi.org/10.3201/eid 2607.201595.

30. Riccò M, Vezzosi L, Balzarini F, Bragazzi NL. Inappropriate risk perception for SARS-CoV-2 infection among Italian HCWs in the eve of COVID-19 pandemic. Acta Biomed. 2020;14;91(3), https://doi.org/10.23750/abm.v91i3.9727.

This work is available in Open Access model and licensed under a Creative Commons Attribution-NonCommercial 3.0 Poland License - http://creativecommons.org/ licenses/by-nc/3.0/p1/deed.en. 